\title{
Energy: the need for technical fixes
}

\author{
Model-based predictions of energy demand and supply are \\ unreliable, since the behaviour of individual producers and \\ consumers cannot be guaranteed. Alvin M. Weinberg (right) of the \\ Institute for Energy Analysis at the Oak Ridge Associated \\ Universities, Tennessee, argues that technical fixes involving increased \\ supply offer the most reliable way of averting an energy crisis
}

I first became acquainted with energy demand modelling when I worked for the Federal Energy Administration in 1974. President Nixon had announced Project Independece: the United States was to import no oil after 1980. The FEA's job was to figure out how to reach this goal, or at least some goal that was consistent in spirit if not in fact with the President's announcement. For this purpose, it set up the most elaborate model the budding art of energy modelling had yet seen. Many millions of dollars were chewed up on two CDC 7500s; their neatly printed graphs showed how energy would be used and how it would be supplied in the United States through the year 1985.

A prime question was the price level of imported oil at which one could expect domestic supply to be so enhanced, and dernand so dampened, as to reach the goal of self-sufficiency. The computers gave a fairly clear answer. At $\$ 16$ per barrel, \$6 per barrel higher than the 1974 OPEC price (at 1979 values), oil imports could fall to zero by 1985 , provided the government encouraged accelerated production of domestic oil. The model predicted that, even without government intervention, US imports in 1980 would be only about 6 million barrels per day, falling to about 5 million barrels per day in 1985. As things turned out, the US imported more than 8 million barrels per day in 1979 even with the price of imported oil a good bit higher than $\$ 16$ per barrel.

Looking back, it is apparent that the FEA model had overestimated the demand elasticity for liquid fuel - the percentage decrease in demand for a given increase in price. The output of the entire model depended critically on the value of this elasticity. Demand elasticities are notoriously uncertain: those used in various models differ by a factor of ten!

Last October, I (along with 200 energy modellers) attended the Dublin meeting on Energy Systems Analysis sponsored by the European Economic Community. The EEC is sponsoring a "super" model that encompasses the entire community; with sub-models applied to each country. At the Dublin meeting the modellers could compare the results of application of the EEC methods to each country.

This effort is of extraordinary scope. Yet, as the modellers themselves conceded, one can hardly depend on its predictions. Unexpected things happen. The Shah is

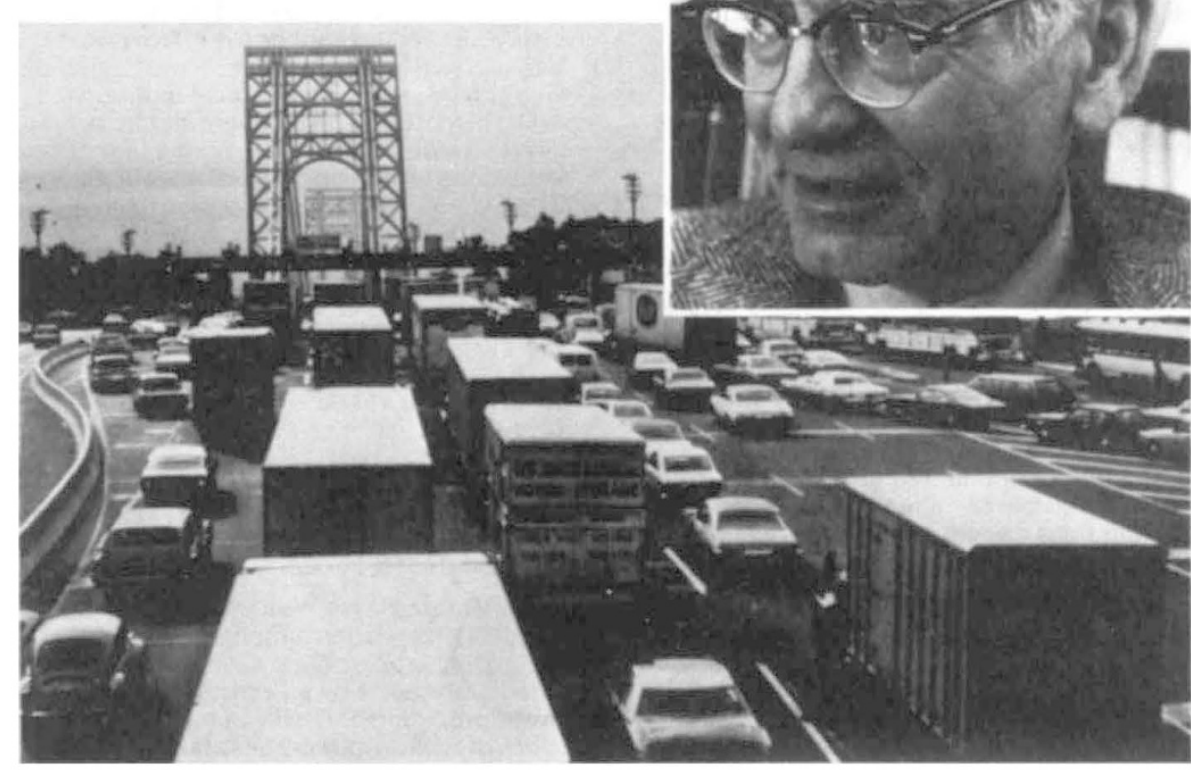

Increased oil prices have not deterred US consumers, so Carter has chosen to develop synfuels

overthrown; people simply don't react the way the models assume they should.

The moral is clear: policymakers must treat models warily. This is hardly an original view. Yet it seems that the modellers in the United States have had remarkable success with the opinionmakers if not, as yet, with the policymakers.

Most of the more recent models tend to stress reduction in demand rather than increase in supply. This viewpoint is promulgated in the recent report of the Harvard Energy Project, Energy Future. The book has already sold more than 100,000 copies. It has been widely acclaimed in the American press as containing both the best appraisal of the energy problem, and the best strategy for its resolution.

To meet the US demand in the late 1980 s, the Harvard study estimates that 8 million daily barrels of oil equivalent (mboe) can be saved by conservation, and 3 mboe by widespread use of solar energy. "Conventional" supply, meaning coal and nuclear, is increased by only $5 \mathrm{mboe}$. These numbers are to be compared with the 37 mboe equivalent total US demand in 1977. Conservation and solar energy, by the late 1980s, are supposed to take care of almost one-third as much energy as was supplied by all energy sources in 1977. Although the Harvard study properly warns that conservation and a transition to "Solar America' depend on innumerable decisions made by countless people, all conserving energy or installing their own solar devices, it leaves the impression that here was a true, and ideologically acceptable, path to energy salvation.

By-contrast, Jimmy Carter's response to the energy situation last June was, to a remarkable degree, supply-oriented: spend $\$ 80$ thousand million for several million barrels per day of synfuel. The President chose to put most of his money on a technical fix: synfuels. How much of the President's proposal will survive in Congress will depend on how much political pressure is generated by those who believe conservation and solar energy come painlessly.

I doubt that the President and his advisers weighed the uncertainties in predictions of demand when they decided to go for increased supply. But I believe their instinct was right. Technical fixes, especially those involving increased supply, require decisions by relatively few people. They finesse the impossibility of knowing how and how quickly 220 million people will react to a change in price.

Obviously the proper course is to increase supply as well as to conserve. This piece of common wisdom seems to be ignored by some of our noisier conservationists. Despite opposition from this segment of the energy community, I hope the President's commitment to augmenting supply will receive the public support it needs to survive in Congress. $\square$ 